\title{
OBSERVATIONS ON 1,078 PERINATAL DEATHS
}

\author{
BY
}

\author{
A. M. STEWART, J. W. WEBB*, AND D. HEWITT
}

From the Social Medicine Unit, Oxford University

\begin{abstract}
A cause of death is the morbid condition or other disease process, abnormality, or injury leading directly or indirectly to death ... . From the standpoint of the prevention of deaths it is important to cut the chain of events or institute the cure at some point. The most effective public health objective, of course, is to prevent the precipitating cause from operating. For this purpose the most useful single statistic is that relating to the underlying cause of death which may be defined as $(a)$ the disease or injury which initiated the train of morbid events leading directly to death, or $(b)$ the circumstances of the accident or violence which produced the fatal injury ... Symptoms or modes of dying such as heart failure, asthenia etc., are not considered to be causes of death for statistical purposes. (W.H.O., 1948).
\end{abstract}

In the vast majority of cases these elementary rules of procedure present little difficulty to the doctor who has to sign a death certificate. Mistakes are sometimes made, but each certificate is carefully scrutinized at the General Register Office and if there is any reason to suppose that the stated cause of death merely describes the mode of dying it is promptly returned for amendment. In the case of stillbirths and neonatal deaths, however, the rules cannot be strictly enforced. The absence of definite signs of disease (or the co-existence of several equally lethal conditions), combined with the difficulty of following intra-uterine events, frequently makes it impossible to express a reasoned opinion as to the cause of death. It is obvious, for example, that prematurity cannot possibly have "initiated the train of events leading directly to death". Nevertheless every year thousands of certificates giving this as the cause of death are accepted by the General Register Office, and "prematurity" regularly takes its place as a cause of death both in official vital statistics and in the international list of diseases.

At first sight certificates which name something more precise, like a congenital defect, as the cause of death seem more informative than those which attribute death to prematurity. But a moment's thought will show that it is the secondary nature of

\footnotetext{
* In receipt of a grant from the Medical Research Council.
}

prematurity and not any vagueness in the term (or any doubt whether a baby should be so described) that makes it so unrevealing as a cause of death. Since maldevelopment, like under-development, is the end-result of an unknown process, even certificates with such precise diagnostic terms as anencephalus and exomphalos do no more than describe a mode of dying.

The realization that a medical classification of stillbirths and neonatal deaths is unsatisfactory has led workers to stress the importance of non-medical conditions, and to study social and genetic factors which (though they will never gain admission to the International list) are nevertheless on a par with some categories now accepted as causes of death (Baird and Illsley, 1953; Douglas, 1950; Karn and Penrose, 1952; Sutherland, 1949; Woolf, 1947). The results of such investigations may eventually provide us with a more satisfactory nomenclature. Meanwhile there is so much confusion about what are proximate and remote causes of death in infancy, and what are merely modes of dying, that it may be of value to take a group of live and dead babies and, without prejudice to the question of causation, compare the frequency of various observations made before, during, and immediately after delivery. With this end in view we have examined the antenatal and obstetrical records of just over a thousand stillbirths and neonatal deaths, and have compared them with the records of an equal number of babies who survived beyond the age of 4 weeks.

\section{Material and Methods}

The records form part of a survey in which five Public Health departments participated. Each centre agreed that data should be collected for two categories:

(1) All stillbirths and neonatal deaths occurring in a given year (1952-3).

(2) All other babies born (to mothers normally resident in the area) on certain stated days of each month. 
Existing records of antenatal, obstetrical, and postnatal supervision were assembled, and Health Visitors were asked to collect certain additional facts when they paid their first postnatal visit to the house. All the records were transcribed onto printed cards and in each area one or two medically qualified persons were responsible for the correct interpretation of the clinical data. The observations were not restricted to any special group of babies; domiciliary and institutional deliveries, multiple and single births, and cases with and without antenatal or obstetrical supervision were included in the survey.

Some regions sent the records of a disproportionately large number of surviving babies, but, to prevent regional factors from affecting the calculations, the present study has used an equal number of live and dead babies from each region.* The cases were distributed as follows:

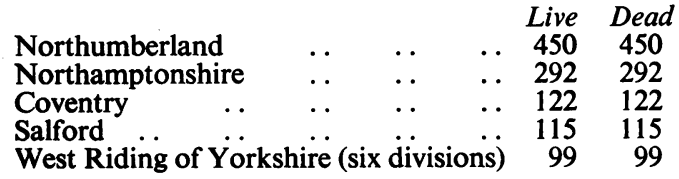

Total number: 1,078 stillbirths and neonatal deaths (Dead Sample) and 1,078 babies who survived to 4 weeks (Live Sample).

Neither sample includes any multiple births but the Dead Sample includes all other available cases.

\section{Age ANd Parity Effects}

Table I shows a preliminary analysis of the material in terms of maternal age and parity. The cells of the Table show:

(1) Total number of live and dead babies whose mothers fell into the stated age and parity group.

(2) Ratio of the number of dead babies to the number of live babies.

(3) Statistical significance of any departure of this ratio from unity. $t$

The Table illustrates two well-established features of perinatal mortality, namely; the above-average risk of death for first babies, and for all infants born to older mothers, particularly first babies.

In the present sample the most favourable condition for survival was enjoyed by the second and third children of a mother who was still under 26 years of age.

Among the propositions which may be based on the figures in Table $I$ is the following:

If babies born to mothers over 33 years of age had suffered no greater risk of death than those born to younger mothers, then about 100 deaths, or 9 per cent. of the total would not have occurred.

\footnotetext{
* An analysis of the stated causes of death revealed no significant differences between the five regions.

$t$ This was assessed by means of a $x^{2}$ comparison of actual and "expected" numbers of live and dead babies, after standardizing for age in the case of parity, and for parity in the case of age.
}

TABLE I

COMPARATIVE DISTRIBUTION BY MOTHER'S AGE AND PARITY OF 1,078 LIVING AND 1,078 DEAD OR STILLBORN INFANTS, SHOWING RATIO OF NUMBER DEAD TO NUMBER LIVING IN EACH GROUP

\begin{tabular}{|c|c|c|c|c|c|}
\hline \multirow{2}{*}{\multicolumn{2}{|c|}{ Age (yrs.) }} & \multicolumn{4}{|c|}{ Parity } \\
\hline & & \multirow{2}{*}{$\begin{array}{l}\text { First } \\
479 \\
1 \cdot 10\end{array}$} & \multirow{2}{*}{$\begin{array}{c}\begin{array}{c}\text { Second or } \\
\text { Third }\end{array} \\
274 \\
0 \cdot 71 * *\end{array}$} & \multirow{2}{*}{$\begin{array}{c}\begin{array}{c}\text { Fourth or } \\
\text { Later }\end{array} \\
27 \\
1 \cdot 45\end{array}$} & \multirow{2}{*}{$\begin{array}{l}\begin{array}{c}\text { All } \\
\text { Parities }\end{array} \\
780 \\
0.95\end{array}$} \\
\hline 25 or Under & $\ldots$ & & & & \\
\hline 26 to 32 & $\ldots$ & $\begin{array}{l}233 \\
1 \cdot 14\end{array}$ & $\begin{array}{l}458 \\
0 \cdot 75^{* *}\end{array}$ & $\begin{array}{l}177 \\
0 \cdot 88\end{array}$ & $\begin{array}{l}868 \\
0 \cdot 87\end{array}$ \\
\hline 33 or Over & . & $\begin{array}{c}68 \\
2 \cdot 40 * *\end{array}$ & $\begin{array}{l}233 \\
1 \cdot 03\end{array}$ & $\begin{array}{l}207 \\
1 \cdot 59 * *\end{array}$ & $\begin{array}{l}508 \\
1 \cdot 36^{* * *}\end{array}$ \\
\hline All Ages . . & $\ldots$ & $\begin{array}{l}780 \\
1 \cdot 18 * *\end{array}$ & $\begin{array}{l}965 \\
0 \cdot 80^{* * *}\end{array}$ & $\begin{array}{l}411 \\
1 \cdot 22\end{array}$ & $\begin{array}{r}2,156 \\
1 \cdot 00\end{array}$ \\
\hline
\end{tabular}

Significance levels:

5 per cent.

1 per cent. **

0.1 per cent. $* * *$

It is of interest to consider the logical parallel between this and another proposition which can be supported by the survey findings:

If babies with congenital defects had suffered no greater risk of death than other babies, then about 257 deaths or 24 per cent. of the total number would not have occurred.

No one would take the first proposition to mean that 9 per cent. of the deaths had been caused by the fact that the mother was over the age of 33. But current usage would allow the latter proposition to be translated into " 24 per cent. of deaths were caused by congenital defects". In neither case can a statement about cause of death be deduced from the original proposition, though it is worth noting that aging of the mother might properly be regarded as an "underlying cause", whereas a congenital defect merely describes a "mode of dying". We suggest therefore that the distinction is based purely on the observation that the case fatality associated with congenital defect is much higher than that associated with excessive age in the mother. That is to say, the basis for the selection of "the cause of death" in a large number of stillbirths and neonatal death certificates is, implicity, no more than a statistical association between certain abnormal findings and the subsequent birth of a dead or moribund infant.

Such being the case, it is clearly important to estimate as precisely as possible the case fatality associated with a number of antecedent events. Tables II-V show the relative frequency of 25 items in the records of the dead and living babies, the total number of times each item was recorded, and an indication whether or not the relative frequency differs significantly from unity. 
The significance tests were based on figures which had been standardized in the same age-parity groups of Table I, but the relative frequencies are deliberately based on "crude" or unstandardized figures, adjusted only for numbers "not stated" in each sample. For two reasons the relative frequencies do not provide an unbiased estimate of the risk of death among affected and unaffected babies. In the first place they take no account of the small number of cases in which manoeuvres such as craniotomy were carried out after the death of the foetus. Secondly, an unbiased estimate of risk would have to take account of the ratio of dead to living infants in the population from which the samples were drawn,* a ratio which has not been considered here.

\section{Risks associated With CERTAin AbNoRmal Events}

From the nature of the investigation it was unlikely that any "new" observations would be made. The interest of the following Tables lies,

TABLE II

COMPARISON OF 1,078 STILLBIRTHS AND NEONATAL DEATHS WITH 1,078 BABIES WHO SUR VIVED TO ONE YEAR Risk of foetal death associated with certain signs and symptoms

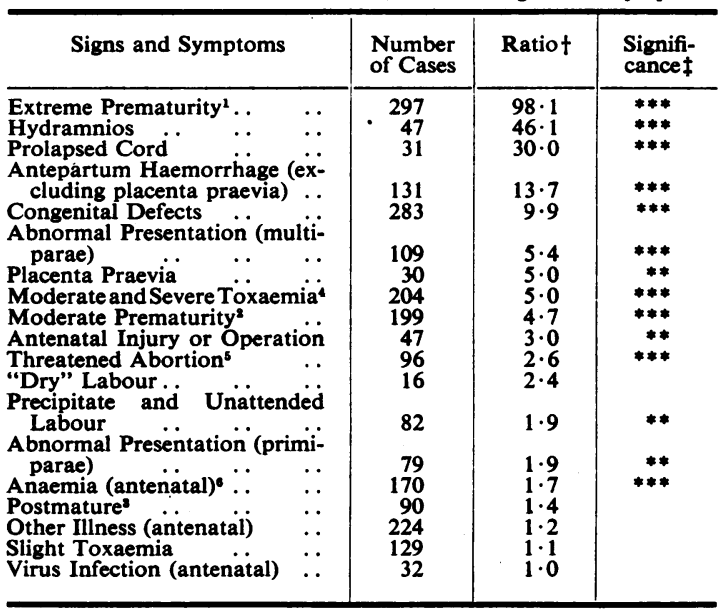

1 Under $4 \mathrm{lb}$. birthweight or born more than 60 days before date of expected delivery.

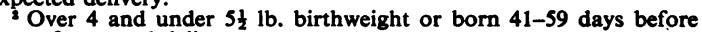
date of expected delivery.

3 Over $10 \mathrm{lb}$. birthweight or born over 30 days after date of expected delivery.

Requiring rest in bed.

- Bleeding per vaginam any time during antenatal period.

- Haemoglobin $=75$ per cent. or less, or mother described as "anaemic".

$t$ i.e. Ratio of the times recorded in the Dead Sample to the times

$\begin{aligned} & \text { recorded in the Live Sample. } \\ & f^{* * *}=P<0.001\end{aligned}{ }^{* *}=0<0.01 \quad=P<0.05$

- Let $\boldsymbol{A}=$ the proportion of affected among the living infants, $B=$ the proportion of affected among the dead infants

$B=$ the proportion of affected among the dead infants,
$D=$ the proportion of dead infants in the population. Also let $K=A+D(B-A)$. Then an unbiased estimate of relative risk would be given by $B(1)$. Then an unbiased estimate of relative a perinatal mortality rate of 40 per thousand, the relative risk for the "moderately premature" infants may be estimated as $4 \cdot 47$, compared with the relative frequency $(B / A)$ in Table II of $4 \cdot 69$, therefore, not in the selection of items which appear as bad risks, but in the attempt to express certain observed facts as measured quantities. The items for which risks have been calculated have been divided into four groups.

The first (Table II) includes a number of signs and symptoms (noted before, during, and after delivery) which are generally recognized as abnormal or likely to lead to difficulties.

The second group (Table III) comprises certain active steps taken by the doctors in charge, presumably because their cases presented unusual or potentially dangerous features.

TABLE III

COMPARISON OF 1,078 STILLBIRTHS AND NEONATAL DEATHS WITH 1,078 BABIES WHO SURVIVED TO ONE YEAR RISK OF FOETAL DEATH ASSOCIATED WITH CERTAIN TYPES OF ACTIVE INTERVENTION

\begin{tabular}{|c|c|c|c|c|}
\hline Intervention & & Number & Ratio & Signifi- \\
\hline $\begin{array}{l}\text { Craniotomy } \\
\text { Internal Manipulation } \\
\text { Forceps (multiparae) } \\
\text { Caesarean Section } \\
\text { External Version }\end{array}$. & $\begin{array}{l}\cdots \\
\cdots \\
\cdots \\
\cdots\end{array}$ & $\begin{array}{l}14 \\
28 \\
33 \\
68 \\
63 \\
90\end{array}$ & $\begin{array}{l}\infty \\
6 \cdot 1 \\
5 \cdot 7 \\
2 \cdot 6 \\
1 \cdot 5 \\
1 \cdot 1\end{array}$ & $\begin{array}{r}* * * \\
* * * \\
* * * \\
* *\end{array}$ \\
\hline
\end{tabular}

The third group (Table IV) is more mixed. Two of the items (habitual abortion and Rhesus factor) are recognized as "causes" of stillbirth, and one (illegitimacy) frequently features in official vital statistics. The fourth item (pre-marital conception) is included because it probably has something in common with illegitimacy.

TABLE IV

RISK OF FOETAL DEATH ASSOCIATED WITH CERTAIN SOCIAL AND CONSTITUTIONAL BACKGROUNDS

\begin{tabular}{|c|c|c|c|}
\hline Background & $\begin{array}{l}\text { Number } \\
\text { of Cases }\end{array}$ & Ratio & $\begin{array}{c}\text { Signifi- } \\
\text { cance }\end{array}$ \\
\hline $\begin{array}{l}\text { Habitual Abortion }{ }^{1} \\
\text { Premarital Conception (legiti- } \\
\text { mate) } \\
\text { Premarital Birth (illegitimate) } \\
\text { Rhesus-Negative (multiparae) }\end{array}$ & $\begin{array}{r}55 \\
94 \\
89 \\
198\end{array}$ & $\begin{array}{l}3 \cdot 2 \\
1 \cdot 8 \\
1 \cdot 4 \\
1 \cdot 0\end{array}$ & $\begin{array}{c}* * * \\
*\end{array}$ \\
\hline
\end{tabular}

${ }^{1}$ Ratio of miscarriages and stillbirths to live birth greater than unity (i.e. more unsuccessful than successful pregnancies).

Table V (overleaf) describes risks associated with different types of maternal physique. It differs from the preceding Tables in that all the mothers belonged to one of the nine body-build groups so that there were bound to be some groups in which the ratio of deaths to survivors was less than unity, and in that none of the nine sub-groups are abnormal, in the usually accepted sense. 
TABLE V

RISK OF FOETAL DEATH ASSOCIATED WITH DIFFERENT TYPES OF MATERNAL PHYSIQUE†

\begin{tabular}{|c|c|c|c|c|c|c|}
\hline Build & \multicolumn{2}{|c|}{ Height } & $\begin{array}{l}\text { Number } \\
\text { of Cases }\end{array}$ & \multicolumn{2}{|c|}{ Ratio } & $\begin{array}{l}\text { Signifi- } \\
\text { cance }\end{array}$ \\
\hline \multirow{3}{*}{ Obese } & short. & . & 39 & $2 \cdot 1^{* *}$ & \multirow{3}{*}{$1 \cdot 6$} & \multirow{3}{*}{$* * *$} \\
\hline & average & .. & 146 & $1 \cdot 5^{*}$ & & \\
\hline & tall & .. & 27 & $1 \cdot 5$ & & \\
\hline \multirow{3}{*}{ Average } & short . & .. & 179 & $1 \cdot 1)$ & \multirow{3}{*}{$1 \cdot 0$} & \\
\hline & average & .. & 1,005 & $1 \cdot 0$ & & \\
\hline & tall. & .. & 207 & 0.7 & & \\
\hline \multirow{3}{*}{ Thin } & short & .. & 105 & $1 \cdot 2)$ & \multirow{3}{*}{$1 \cdot 0$} & \\
\hline & average & & 180 & $1 \cdot 0$ & & \\
\hline & tall & .. & 65 & 0.8 & & \\
\hline
\end{tabular}

t Description given by Health Visitors 3-4 weeks after delivery.

The grave prognosis attached to such abnormal signs as hydramnios, prolapsed cord, antepartum bleeding, and congenital defects is clearly demonstrated in Table II, as is also the very different type of risk associated with severe and mild grades of prematurity and toxaemia. In the live sample abnormal presentations (other than cord) were nearly three times as common among primiparae as among multiparae, but for the latter group the risk of foetal death was much greater and (in the present series) actually exceeded the risk associated with placenta praevia. Abnormal presentations in first births were nearly twice as hazardous as normal presentations and about as dangerous as having a precipitate delivery without supervision.

One of the most disappointing features of the survey was the number of cases returned with no haemoglobin records. A large majority of the mothers had had at least one blood test-as witnessed by the large numbers of Kahn tests, Rhesus factors, and ABO blood groups-but only in one region was a hâemoglobin value automatically recorded. Nevertheless, it is clear that anaemia in the mother has unfortunate repercussions on the baby, for in the group of 170 cases where either the haemoglobin was (on one occasion only) less than 76 per cent. or the mother was said to be "anaemic" there was an excess of infant deaths of nearly 70 per cent.

The survey also showed that routine antenatal records cannot be relied upon as sources of morbidity data in the antenatal period. Routine testing of the urine and blood was done at all the clinics, but there was no guarantee that minor diseases (other than slight toxaemia of pregnancy) were consistently recorded. The whole sample yielded 47 examples of major injury or operation,
32 cases of virus infection (including influenza), and 224 other illnesses. In the accident and operation group the number of deaths recorded was nearly three times greater than the "expected" number, but for the virus infections and other illnesses there was no appreciable increase in general risk. The number of cases in which there was premature loss of the amniotic fluid (16) was too few to obtain a significant result, but in this small group the proportion of deaths and survivors was roughly the same as for the 96 cases in which bleeding per vaginam was recorded some time during the antenatal period.

Five types of active intervention are analysed in Table III. One of these (craniotomy) is, by definition, universally fatal, and one (forceps) has been separately studied in primiparae and multiparae. No special risk attached to the use of forceps in first births but when applied to later births the infant frequently died either during or shortly after delivery. Approximately half of the Caesarean sections were begun before and half after the onset of labour. This proportion applied to both primiparae and multiparae, and in both cases the operation was performed more than two and a half times as frequently in the dead as in the living sample. External version had been attempted in 63 cases and for this group the risk of foetal death was 45 per cent. above standard.

A question which is frequently asked is "What are the chances against a woman, who is pregnant and has had several miscarriages or stillbirths, producing a live baby?". In the present sample, where habitual abortion was defined as "more unsuccessful than successful pregnancies" (and therefore included primiparae who had had one miscarriage), there was three times the normal chance that the baby would be dead within a month of delivery. This is about the same as the overall risk for abnormal presentations (all parities combined). Several deaths were ascribed to haemolytic disease, but these did not bring about a general excess of deaths among Rhesus-negative multiparae.

In England and Wales, the stillbirth and neonatal death rates among illegitimate babies, though still excessive, have been falling faster than the national rates. In the present sample the survival rate for illegitimate infants was slightly below par, but the difference between the observed and expected number of deaths was not statistically significant. There were, however, at least 94 mothers who married after their babies were conceived but before they were born, and in this group the number of stillbirths and neonatal deaths was significantly greater than the expected number. 
Baird and Illsley (1952) have reported an inverse association between height of mother and foetal death rate. The classification of height in Table $\mathrm{V}$ is based, not on precise measurements, but on the Health Visitor's description of the mother as "tall", "medium", or "short". Nevertheless these three groups were found to differ significantly, with tall mothers again showing to advantage. Health Visitors were also asked to characterize the build of each woman , as "obese", "medium", or "thin" "Medium" and "thin" women did not differ in their ability to produce live infants, but among the 212 women described as "obese" the risk of stillbirth or neonatal death was 60 per cent. above the standard. This risk appeared to be still greater among the women who were described as both "obese" and short".

\section{Virus Infections in the Antenatal Period}

A topic which has stimulated much interest in recent years is the possibility of an association between virus infection during pregnancy and the subsequent birth of a malformed infant. It has been suggested that some of the earlier investigations of this topic are inadequate because the medical history (having been collected retrospectively) may have been biased by the known outcome of the pregnancy (Logan, 1951). The present investigation is not open to this criticism, for the records of antenatal illnesses, though admittedly incomplete, were compiled before delivery. In the live sample the congenital malformations were mainly of a trivial and uninteresting nature*. There were, however, in the dead sample sixteen cases in which the mother was known to have had a virus infection. In this small group there were seven babies with congenital malformations and nine without. According to the overall frequency of congenital malformations in the

\footnotetext{
- One mother who had influenza in the second month of pregnancy produced a baby with congenital heart disease. As the baby survived to 10 weeks it is not included in the following analysis.

The sixteen virus infections in the dead sample included eleven cases of influenza, four of rubella, and one of infective hepatitis. Three cases were undated, six occurred in the first 3 weeks of pregnancy, and seven in the later months.
}

dead sample as a whole, the "expected" numbers were $3 \cdot 8$ and $12 \cdot 2$ respectively. These numbers are too small for the ordinary $\chi^{2}$ treatment, but an exact one-tailed test based on the expansion of $(0.238+0.762)^{16}$ shows that the observed and "expected" numbers do in fact differ at the 5 per cent. level of significance.

\section{SUMmary}

Certificates of stillbirth and neonatal death frequently contain terms which may be said to described the "mode of dying" rather than the "cause of death". This is inevitable while all but a handful of the true causes remain unknown. The justification for the terms in current use is a statistical one (i.e. a high case fatality associated with certain events noted before, during, or shortly after delivery). In an attempt to make this situation more explicit a comparison has been made of the frequency of some of these events in the records of 1,078 dead babies and of an equal number of babies who survived to the age of 4 weeks. None of the findings which emerged are altogether new, but it is hoped that the form of the analysis may set familiar facts in a fresh perspective and so help to stimulate a more radical approach to the medical problems of perinatal mortality.

It is unfortunately not possible to mention by name all the people who took part in the survey, but we hope they will identify themselves with Dr. Tilley (Northumberland), Dr. C. M. Smith (Northamptonshire), Dr. Clayton (Coventry), Dr. Sproul (Salford), and Dr. Wood-Wilson (West Riding of Yorkshire), who organized the field work and to whom we offer our most grateful thanks.

We are also indebted to the Nuffield Provincial Hospitals Trust who contributed generously towards the expenses of the investigation.

\section{REFERENCES}

Baird, D., and Illsley, R. (1953). Proc. Roy. Soc. Med., 46, 53. Douglas, J. W. B. (1950). J. Obstet. Gynaec., Brit. Emp., 57, 143. Karn, M. N., and Penrose, L. S. (1951). Ann. Eugen. (Camb.), 16, 147. Logan, W. P. D. (1951). Brit. Med. J., ii, 641.

Sutherland, I., (1949). "Stillbirths, their Epidemiology and Social Significance". Oxford University Press, London.

Woolf, B. (1947). British Journal of Social Medicine, 1, 73.

World Health Organization (1948). "International Statistical Classification of Diseases, Injuries, and Causes of Death". W.H.O., Geneva. 